\title{
Evaluación Fisicoquímica y Microbiológica de una Conserva de Flor de Cabuya Negra (Agave Americana) con Diferentes Niveles de Ácido Acético en el Líquido de Cobertura
}

\author{
Physical, Chemical, and Microbiological Evaluation of a \\ Preserved Black Cabuya Flower (Agave Americana) with \\ Different Levels of Acetic Acid in the Covering Liquid
}

\author{
Miguel Ángel Enríquez ${ }^{1}$ \\ ${ }^{1}$ Universidad Estatal Amazónica, Puyo, Ecuador \\ menriquez@uea.edu.ec
}

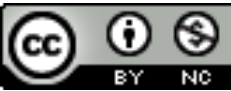

Enviado:

$2020 / 12 / 20$

Aceptado:

$2021 / 01 / 28$

Esta obra está bajo una licencia internacional

Creative Commons Atribución-NoComercial 4.0.

Publicado: $\quad 2021 / 06 / 30$

\section{Resumen}

Esta investigación tuvo como objetivo determinar los niveles óptimos de ácido acético en la formulación de un líquido de gobierno para la conservación de la flor de cabuya (Agave americana), que es una planta que crece en lugares secos y áridos de la región andina. La concentración del $30 \%$ de ácido acético obtuvo un mejor parámetro de aceptabilidad, tomando en cuenta que, mientras pasa el tiempo de almacenamiento, el pH disminuye y la acidez se incrementa. En conclusión, se determinó que la concentración mencionada es la que mejor puntuación obtuvo por los catadores.

Palabras clave: organoléptico, ácido acético, especies, agave, acidez.

\begin{abstract}
This research aims to study different levels of acetic acid in the formulation of a government liquid for the conservation of the Cabuya flower (Agave americana), which is a plant that grows in arid places of the Andean region. A concentration of $30 \%$ of acetic acid obtained a better parameter of acceptability; considering the passage of shelf life, the $\mathrm{pH}$ levels decrease, and the acidity levels increase. In conclusion, the defined concentration obtains the best score by tasters.
\end{abstract}

Keywords: organoleptic, acetic acid, species, agave, acidity.

Sumario: 1 Introducción, 2 Metodología, 3 Resultados y Discusión, 4 Conclusiones.

Como citar: Enríquez, M. A. (2021). Evaluación Fisicoquímica y Microbiológica de una Conserva de Flor de Cabuya Negra (Agave Americana) con Diferentes Niveles de Ácido Acético en el Líquido de Cobertura. Revista Tecnológica - Espol, 33(1), 84-91.

http://www.rte.espol.edu.ec/index.php/tecnologica/article/view/779 


\section{Introducción}

El género A. americana pertenece a la familia agavaceae, que incluye numerosas especies originarias de las zonas desérticas de América. La mayor parte de las plantas son monocárpicas; su desarrollo y maduración toman un tiempo estimado de entre 10 a 12 años, lo que permite apreciar que la planta florece una sola vez en su vida y, después de la floración y maduración de los frutos, muere. El agave es una planta originaria de América Central, aclimatada y extendida por todo el litoral mediterráneo; es perenne y presenta un rizoma muy robusto de hojas que llegan a alcanzar metros de longitud y flores amarillo-verdosas. El agave americana fue utilizado desde la época prehispánica para fines alimenticios, como forraje, medicamento y material de construcción. El agave es parte importante del legado histórico y cultural y fuente importante de empleo y generación de recursos económicos de algunas familias campesinas e indígenas (Loachamín, 2015; Meza, 2011).

Los agaves se pueden propagar mediante bulbillos, que son brotes vegetativos que se generan en los pedúnculos florales, en el tallo y entre una hoja y otra (brote axial). Sin embargo, para el agave esta práctica no es usual, ya que no es común hallar dichos brotes vegetativos, o son muy escasos. Principalmente se utilizan los hijuelos que nacen desde los rizomas de la planta madre, para posteriormente ser trasplantados cuando alcanzan una altura hasta de $50 \mathrm{~cm}$ (Figueroa y Sosa, 2015).

La palabra "agave" fue usada por Charles Linneo en 1753 para caracterizar a este género por su habilidad de desarrollarse bajo condiciones extremadamente secas, aunque también pueden encontrarse en otros ecosistemas con elevada humedad. En México existen alrededor de 135 especies de agave, lo que corresponde al $75 \%$ de este tipo de vegetación; entre las especies más importantes se pueden mencionar: A. tequilana, que sirve para la producción de tequila; A. Salmiana; A. angustifolia; A. americana y algunas otras especies que son cultivadas comercialmente para la producción del mezcal (López y Mancilla, 2007; Ortiz et al., 2009; De León et al., 2006).

El agave americana crece en las regiones áridas y semiáridas de América del sur, América central y algunas partes de Europa. Esta planta se distribuye geográficamente en los países de región Andina como Bolivia, Colombia, Chile, Ecuador, Panamá, Perú y Venezuela; en la Figura 1 se detalla su inflorescencia.

\section{Figura 1}

\section{Inflorescencia del agave americano. (Duque Sánchez, 2013)}

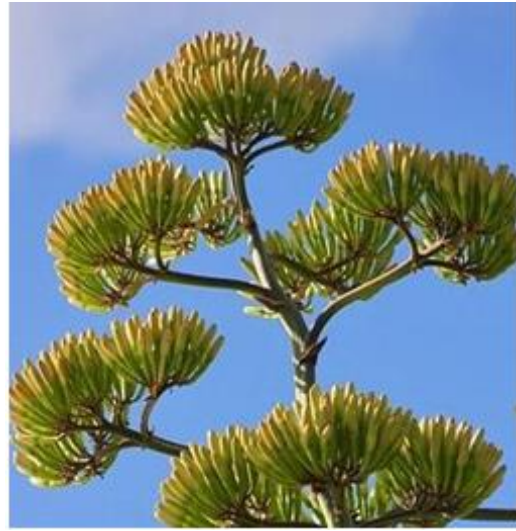

En la alimentación se utilizan las flores tiernas del penco para crear uno de los más deliciosos encurtidos en vinagre. Se las suele llamar comúnmente "alcaparras de penco", aunque su nombre ancestral es "kirillas". Según algunos entendidos son superiores en sabor a las verdaderas alcaparras procedentes de Europa. El penco tiene un regalo escondido, el chawarmishky o savia dulce del corazón de la planta. "Chawar" significa penco, pero es también el verbo extraer u ordeñar. "Mishky" significa dulce. En México se le denomina aguamiel o tlachique.

Para poder sacar el chawarmishky, el penco necesita tener entre 12 y 15 años. Se sabe que está listo para poder ser "chawado" cuando sus hojas empiezan a doblarse y está listo para que crezca el 
"chawarquero", o el tallo de sus flores. Según la tradición en una noche oscura sin avisar a nadie el hombre debe acudir al penco y hacer un hueco entre la cuarta y la quinta hoja, raspando, agregando agua, y dejándolo tapado. Después de 8 días, la mujer acude a la planta durante el día, saca y tira el agua acumulada en el hueco, y raspa un poco más del interior. A partir de entonces se acumulará constantemente un agua dulce, semejante a un jugo, que se puede recoger de 2 a 3 veces al día, durante aproximadamente cuarenta días. Durante todo este periodo, el hombre no puede acercarse a la planta. (Duque Sánchez, 2013).

En los alimentos conservados mediante el calor se producen reacciones tanto físicas como químicas que influyen en el valor nutritivo (Rees y Bettison, 1994). La posibilidad de usar métodos de conservación basados en más de un principio reduce la intensidad del tratamiento térmico y mantiene las cualidades organolépticas en el producto final (Carrión, 1995). Los métodos de conservación bien aplicados brindan al consumidor la posibilidad de satisfacer sus necesidades de consumo (Enríquez, 2019).

El encurtido o conserva es un procedimiento antiguo de conservación de alimentos. Civilizaciones antiguas como la egipcia conocían ya la fermentación. Son muchas variedades de frutas y verduras las que pueden encurtirse, no solo con el objetivo de conservar el alimento sino también de mejorar su sabor. Las clases de productos encurtidos son muchas, las más comunes son los encurtidos de pepino y otros vegetales; las frutas encurtidas, en particular peras, naranjas y ciruelas (Hernández et al., 2009). El encurtido es una semiconserva alimenticia de gran importancia debido a su alto consumo por parte de la población durante los últimos años. Los vegetales que se utilizan tradicionalmente para la elaboración de encurtidos son el pimentón, calabacín, vainilla, zanahoria, cebolla, ají, coliflor y pepino, entre otros. El encurtido en su definición más amplia es el uso de sal, vinagre o una solución de especias para preservar y dar sabor único a un alimento que se adapte al proceso. La vida de anaquel de los encurtidos depende de los agentes preservadores y de la pasteurización cuando esta se emplea (Duran Ramírez, 2010).

La materia prima puede someterse a fermentación ácido láctico o bien no fermentarse. Ello puede lograrse mediante la adición de sal común, que origina una fermentación láctica espontánea del azúcar del vegetal (encurtidos fermentados), o añadiendo directamente ácido acético o vinagre al vegetal (encurtidos no fermentados); de igual forma pueden elaborarse numerosos tipos de encurtidos mediante adiciones de azúcares, especias, esencias y aromas, pero siempre con presencia de vinagre, lo que constituye la característica más importante del encurtido. Los encurtidos, independientemente de que se fermenten o no, pueden pasteurizarse para mejorar su conservación (Hernández, 2003).

El propósito de la investigación consisitió en buscar alternativas comestibles para la flor de cabuya, mediante un método de conservación por regulación de acidez, para posteriormente someterla a los análisis físico- químicos y organolépticos.

\subsection{Localización}

\section{Metodología}

La investigación se llevó a cabo en la Universidad Estatal Amazónica. ubicada en el Km 2 1² de la vía Puyo a Tena, paso lateral.

\subsection{Preparación de la materia prima}

Flor de Cabuya. - una vez seleccionada la materia prima, se ablanda con un proceso térmico a $82^{\circ} \mathrm{C}$ durante 2 minutos, seguido de un proceso de choque térmico con agua fría $\left(3-5^{\circ} \mathrm{C}\right)$; aquí inicia el proceso de desamargado.

\subsection{Formulación del líquido de gobierno}

Se utilizaron 3 niveles de ácido acético 10, 20 y 30 \%. Este proceso se generó en 3 fases: acondicionamiento de materias primas, análisis y los ensayos.

Los Tratamientos del proceso están determinados en la Tabla 1. 
Tabla 1

Tratamientos

\begin{tabular}{|c|c|c|c|c|}
\hline Producto & Unidad & T1 & T2 & T3 \\
\hline Flor de cabuya & g & 0.250 & 0.250 & 0.250 \\
\hline Agua & $\mathrm{cc}$ & 0.121 & 0.108 & 0.094 \\
\hline Ácido acético & $\mathrm{cc}$ & 0.013 & 0.027 & 0.040 \\
\hline Sal & $\mathrm{g}$ & 0.034 & 0.034 & 0.034 \\
\hline Pimienta negra & g & 0.011 & 0.011 & 0.011 \\
\hline Azúcar & $\mathrm{g}$ & 0.054 & 0.054 & 0.054 \\
\hline Ajo en polvo & g & 0.013 & 0.013 & 0.013 \\
\hline $\begin{array}{l}\text { Glutamato mono } \\
\text { sódico }\end{array}$ & $\mathrm{g}$ & 0.004 & 0.004 & 0.004 \\
\hline Total & & 0.500 & 0.500 & 0.500 \\
\hline
\end{tabular}

Fuente: Elaboración propia

\subsection{Análisis}

En la Tabla 3 se definen análisis físicoquímicos ( $\mathrm{pH}$ y acidez), microbiológicos (coliformes totales) y organolépticas (color, apariencia, olor y textura). El análisis se realizó a personas entrenadas previamente (estudiantes de la escuela de Ingeniería Agroindustrial del noveno semestre), a los jueces, se le asignó a cada uno las muestras $(10 \mathrm{~g})$ previamente codificadas, acompañados de un vaso con agua para que beban entre cada muestra, más un pedazo de manzana para que limpie las papilas gustativas y la hoja de evaluación mediante una escala hedónica definida del 1 al 5 (1=pésimo, 2=malo, 3=regular, 4=bueno, $5=$ excelente), el método utilizado es el test triangular que permite a los jueces medir las propiedades sensoriales de los alimentos, diferencias de materias primas, y en general, muy útil para determinar pequeñas diferencias.

\subsection{Valoración Organoléptica}

\section{Resultados y Discusión}

En la Tabla 2 se observa los siguientes parámetros: color. - mientras más ácido acético se añada al líquido de gobierno existe una decoloración del producto, por lo que en los 3 niveles se observa una puntuación de 2,32 al 2,45 y no es significativo, el olor en este parámetro se vio afectado estadísticamente por efecto de los niveles de ácido acético se determinó una variación de valores entre 2.28 del tratamiento 1 al 2.79 del tratamiento 3, el olor es agradable según se incrementa la concentración, apariencia, la textura y el sabor no presentan diferencia significativa, según se detalla en la Tabla 2.

Tabla 2

Valoración organoléptica

\begin{tabular}{|l|c|c|c|c|c|c|c|c|c|c|c|}
\hline $\begin{array}{l}\text { Parámetro } \\
\text { s }\end{array}$ & $\mathbf{1 0 , 0 \%}$ & & & $\mathbf{2 0 , 0 \%}$ & & & $\mathbf{3 0 , 0 \%}$ & & & p & sig \\
\hline & $\mathrm{X}$ & $\mathrm{D} . \mathrm{E}$ & & $\mathrm{X}$ & $\mathrm{D} . \mathrm{E}$ & & $\mathrm{X}$ & $\mathrm{D} . \mathrm{E}$ & & & \\
\hline Color & 2,32 & 0,69 & $\mathrm{a}$ & 2,49 & 0,72 & $\mathrm{a}$ & 2,45 & 0,72 & $\mathrm{a}$ & 0,3537 & Ns \\
\hline Apariencia & 2,40 & 0,68 & $\mathrm{a}$ & 2,53 & 0,72 & $\mathrm{a}$ & 2,60 & 0,77 & $\mathrm{a}$ & 0,1641 & Ns \\
\hline Olor & 2,28 & 0,83 & $\mathrm{a}$ & 2,53 & 0,69 & $\mathrm{ab}$ & 2,79 & 0,78 & $\mathrm{~b}$ & 0,0072 & $* *$ \\
\hline Textura & 2,62 & 0,74 & $\mathrm{a}$ & 2,79 & 0,75 & $\mathrm{a}$ & 2,81 & 0,65 & $\mathrm{a}$ & 0,3065 & $\mathrm{Ns}$ \\
\hline Sabor & 2,45 & 0,80 & $\mathrm{a}$ & 2,81 & 0,74 & $\mathrm{a}$ & 2,79 & 0,88 & $\mathrm{a}$ & 0,0530 & Ns \\
\hline Total & 12,06 & 2,44 & $\mathrm{a}$ & 13,15 & 2,72 & $\mathrm{ab}$ & 13,43 & 2,58 & $\mathrm{~b}$ & 0,0214 & $*$ \\
\hline
\end{tabular}

Fuente: Elaboración propia 


\subsection{Valoración de acidez y pH}

En la Tabla 3 se presentan los resultados de los parámetros físicoquímicos medidos en relación con la concentración del líquido de gobierno.

Tabla 3

Valoración de acidez y pH por el contenido de ácido acético

\begin{tabular}{|c|c|c|c|c|c|c|c|c|c|c|}
\hline Parámetros & $10,0 \%$ & & $20,0 \%$ & & $30,0 \%$ & & C.V & E. Estand. & Prob. & sig \\
\hline Acidez & 7,48 & $\mathrm{a}$ & 7,49 & $\mathrm{a}$ & 7,53 & $\mathrm{a}$ & 0,51 & 0,002 & 0,2796 & ns \\
\hline $\mathrm{pH}$ & 4,13 & $\mathrm{a}$ & 4,12 & $\mathrm{a}$ & 4,1 & $\mathrm{a}$ & 0,57 & 0,001 & 0,324 & ns \\
\hline
\end{tabular}

E. Estand.: Error estándar

$\mathrm{P}>0.05$, No existen diferencias estadísticas de acuerdo al ADEVA

Fuente: Elaboración propia

En la Tabla 4 se presenta un ADEVA de los parámetros en relación al tiempo de conservación.

Tabla 4

Valoración de acidez y pH por el tiempo de conservación

\begin{tabular}{|c|c|c|c|c|c|c|c|c|c|c|}
\hline Parámetros & 15 días & & 30 días & & 45 días & & C.V & E. Estand. & Prob. & Sig \\
\hline Acidez & 7,47 & $\mathrm{a}$ & 7,5 & $\mathrm{a}$ & 7,54 & $\mathrm{a}$ & 0,42 & 0,001 & 0,0907 & ns \\
\hline $\mathrm{pH}$ & 4,14 & $\mathrm{a}$ & 4,12 & $\mathrm{a}$ & 4,10 & $\mathrm{a}$ & 0,44 & 0,000 & 0,0672 & ns \\
\hline
\end{tabular}

Fuente: Elaboración propia

En la medición de $\mathrm{pH}$ se observa que a medida que transcurre el tiempo de conservación el pH disminuye y la acidez se incrementa, así se evidencia que en los tratamientos que a los 15 días tuvo un pH de 4.14 y una acidez de 7.47, a los 30 días pH 4.12, acidez 7.5 y a los 45 días 4.10 pH y 7.54 de acidez. Según González et al. (1980) el producto final envasado que, frecuentemente, se distribuye en los mercados europeos presenta valores de $\mathrm{pH}$ que oscilan entre 3,1 y 3,95 unidades; una acidez libre, principalmente acética, del 0,87 al 3,87\%; un contenido en cloruro sódico del 1,2 al 5\% y, en el caso de los agridulces, alrededor del 8-10\% de azúcares solubles. Aligizaki realiza en Grecia un estudio práctico que consiste en fermentar los pimientos, pelados con hidróxido sódico y lavados posteriormente con agua o salmuera acidulada, en una salmuera de más baja graduación, alrededor del $10 \%$ de NaCI, con control de $\mathrm{pH}$, alrededor de 3 a 3,4 unidades, mediante adición de ácido láctico, en condiciones de anaerobiosis, para evitar el desarrollo de mohos y levaduras superficiales, y atribuye a ciertas levaduras fermentativas, del género Saccharomyces, las excelentes características organolépticas del producto obtenido (Fernández, 1969). Investigaciones posteriores de Minguez et al. (1970) confirman que este procedimiento, utilizando, concentraciones de sal entre 10 y $13 \%$ de $\mathrm{NaCI}$, y valores controlados de $\mathrm{pH}$ entre 3 y 4 unidades, da lugar a un producto final de buena textura, que evita la presencia de materia fermentable en la aceituna rellena, y se demuestra que las levaduras son los microorganismos responsables de la fermentación. La presencia de bacterias lácticas se considera, en este caso, accidental (González et al., 1972) identifican en el proceso de fermentación espontánea, como especies más representativas, las siguientes: Hansenula subpelliculosa, Saccharomyces lactis, H. anómala, S. roxii, Hanseniaspora valbyensis, y S. cerevisiae, entre las esporígenas, y Candida Krusei, KIoeckera apiculata y Torulopsis famata, entre las no esporígenas.

\subsection{Valoración microbiológica}

Al realizar el proceso de elaboración del producto se tomó mucho en cuenta la inocuidad generando como resultado la no presencia de microorganismos en el producto final, según se presenta los resultados en la Tabla 5. Según Etchells et al. (1975) describen tres grupos de microorganismos presentes: bacterias coliformes, bacterias lácticas y levaduras. Algunas de las coliformes pueden producir abundantes gases $\left(\mathrm{H}^{\wedge}\right.$ y $\left.\mathrm{COg}\right)$ y ser responsables de alteraciones importantes en la estructura de los frutos, similares a las encontradas en las aceitunas verdes de mesa, y conocidas como ampollado, 
vejigas, anillado y alambrado. Un control del valor de $\mathrm{pH}$, mediante la correspondiente acidificación inicial de la salmuera, da buenos resultados para la rápida eliminación de estos gérmenes. La importancia de este sistema de preparación y conservación de alimentos radica en varios hechos fundamentales: a) permite la elaboración de productos con características sensoriales muy especiales y definidas, mayoritariamente aceptadas por un mercado consumidor amplio, no sólo como alimento en sí, sino como aperitivo selecto, complemento de delicados menús y bebidas alcohólicas típicas; b) permite, igualmente, la conservación durante largo tiempo de materias primas, para ser preparadas finalmente cuando el mercado lo demande, y evitando así las dificultades, a veces insalvables, de elaborar grandes cosechas, dentro del reducido intervalo de tiempo que marca el periodo de recolección; c) constituye un medio de elaboración de bajo consumo de energía, puesto que. por las características finales del producto, bajo valor de $\mathrm{pH}$ y acidez relativamente alta no requiere, en una gran parte de los casos, proceso térmico alguno, y todo lo más, una simple pasterización es suficiente, en lugar de una esterilización; y d) como consecuencia del hecho anterior, se retienen más fácilmente en el producto los nutrientes, algunos de ellos lábiles al calor, y se mantienen mejor determinadas propiedades físicas, tan importantes como el color y la textura (Fleming, 1982). En el orden secuencial, dictado por la Naturaleza, preceden, generalmente, a las bacterias lácticas, las aerobias Gram negativas, frecuentemente presentes en los propios vegetales, en el agua, etc., productoras en muchos casos de alteraciones gaseosas, pero que, en ciertos aspectos, preparan naturalmente, con un moderado descenso inicial del valor de $\mathrm{pH}$ del medio, el camino a sus sucesoras (Rodrigo et al., 1984). Durante la fermentación, el desarrollo de los microorganismos se lleva a cabo mediante una compleja interacción de diversos factores: $\mathrm{pH}$, sal, ácidos orgánicos, actividad del agua, temperatura, potencial rédox, oxígeno y dióxido de carbono. Con algunas variaciones, la fermentación de todos los alimentos vegetales sigue un patrón parecido, que consta de un crecimiento secuencial de bacterias acido-lacticas que incluyen Leuconostoc-mesenteroides, Lactobacillus brevis, Pediococcus acidilactici, Pediococcus pentosaceus y Lactobacillus plantarum. Se han observado otras lácticas, como Enterococcus faecalis, pero no son importantes en la fermentación (Santolaya, 2016).

Tabla 5

Resultados microbiológicos

\begin{tabular}{|c|c|c|c|c|c|c|}
\hline \multirow{2}{*}{ CONTROL } & \multicolumn{5}{|c|}{ UFC/g 10^1 } \\
\cline { 2 - 7 } & Tratamiento 1 & \multicolumn{2}{c|}{ Tratamiento 2 } & \multicolumn{2}{c|}{ Tratamiento 3 } \\
\hline \multirow{2}{*}{ tiempo (Días) } & $\mathbf{a}$ & $\mathbf{b}$ & $\mathbf{a}$ & $\mathbf{b}$ & $\mathbf{a}$ & $\mathbf{b}$ \\
\hline 15 & 0 & 0 & 0 & 0 & 0 & 0 \\
\hline 30 & 0 & 0 & 0 & 0 & 0 & 0 \\
\hline 45 & 210 & 150 & 80 & 60 & 50 & 70 \\
\hline \multicolumn{7}{|c|}{ Fuente: Elaboración propia } \\
\hline
\end{tabular}

\section{Conclusiones}

Con los datos obtenidos en la investigación determinamos que la utilización de ácido acético en la conservación de vegetales es de vital importancia debido a que la carga microbiana es baja en los tiempos analizados esto se debe a su poder antimicrobiano y regulador de $\mathrm{pH}$, en cuanto a la valoración organoléptica la mayor puntuación obtuvo el tratamiento con $30 \%$ de ácido acético.

La utilización de ácido acético en la formulación del líquido de gobierno influyó en la conservación de la flor de cabuya negra positivamente, tomando en cuenta que en un medio acuoso acido se eliminan los microorganismos, este se debe al crecimiento secuencial de bacterias acido lácticas.

El agave en el Ecuador es utilizado para extraer el chawarmishki de forma general, la conservación por regulación de acidez permite el aprovechamiento de subproductos de la planta como son las flores y brindar una oportunidad comestible a la comunidad. Según Enríquez (2018), el principal 
objetivo de la conservación de los alimentos es mantenerlos en perfectas condiciones higiénicas y proteger sus cualidades reológicas y organolépticas.

\section{Referencias}

Loachamín, C. (2015). Elaboración De Biocombustibles A Partir De Dos Variedades De Agave; Agave Negro Y Agave Blanco Con Dos Tipos De Fermento En Los Zumos, A Dos Tiempos Diferentes. Latacunga: Universidad Técnica De Cotopaxi.

Meza, V. (2011). Obtención De Una Bebida Isotónica Nutritiva Carbonatada A Partir Del Extracto Del Penco De Cabuya Negra. Ambato: Universidad Técnica De Ambato.

Figueroa, M., \& Sosa, E. (2015). Caracterización Microbiológica Y Química De La Savia De Agave Americana L. (Cabuya Negra) De Eco tipos De Las Provincias De Pichincha Y Cotopaxi. (Tesis De Grado). Universidad San Francisco De Quito. Quito. Ecuador.

López, M., \& Mancilla, N. (2007). The nature of fructooligosaccharides in Agave plants. Recent Advances in Fructoologosaccharides Research. 2: 47-67.

Ortiz, R., Williams, P., Belleville, M., \& Doco, T. (2009). Presence of rhamnogalacturonan II in the juices produced by enzymatic liquefaction of Agave pulquero stem (Agave mapisaga). Carbohyd. Polym. 77: 870-875.

De León, A., González, L., Barba, A., Escalante, P., \& López, M. (2006). Characterization of volatile compounds of mezcal, an ethnic alcoholic beverage obtains from Agave salmiana. J. Agr. Food Chem. 54: $1337-1341$

Duque Sánchez, J. C. (2013). Evaluación de tres métodos de reproducción del penco azul (agave americana), en la parroquia Tocachi cantón Pedro Moncayo provincia Pichincha. Quito.

Rees, J., \& Bettison, J. (1994). Procesado térmico y envasado de los alimentos. Zaragoza. Acribia. 288 p

Carrión, M. (1995). Manual de Practica en tecnología de conservas vegetales. Cuenca: I.I.C.T. de la Universidad de Cuenca.

Enríquez, M. (2019). Obtención de productos frutícolas deshidratados; tomate de árbol (Cypomandra betacea l) y guayaba (Psidium guajaba ), mediante el empleo de un secador solar con colector plano. Revista Perfiles, v. 22 pp. 12-19.

Hernández, M., Barrera, J., Martínez, O., Fernández Trujillo, J. (2009). Postharvest quality of arazá fruit during low temperature storage. Food Science and Technology, v.42, pt. 879-884.

Duran Ramírez, F. (2010). La Biblia de las Recetas Industriales. Formulas y Procedimientos al Alcance de Todos. Editorial: Grupo Latino Editores.

Hernández, A. (2003). Microbiología industrial. San José, Costa Rica: EUNED.

Anzaldua, A. (1994). La evaluación sensorial de los alimentos en la teoría y la practica Ciencia y tecnología de los alimentos (primera edision ed.). Zaragosa -España: Acribia.

Etchells, J. L., Fleming. H. P., \& Bell. T.A. (1975). Factors influencing the growth of lactic acid bacteria during brine fermentation of cucumbers. Lactic acid bacteria in beverages and food, pp 281-305.- Carr. J. G.. Cutting C. V. and Whiting. G. 0. (Eds.). Academic Press. New York.

González, F., Rejano, L., Duran, M. C., \& Fernández, M. J. (1980). El empleo del ácido láctico en la elaboración de pepinillos. Grasas y Aceites 31, pp. 13-21.

Fernández, M. (1969). Elaboración de aceitunas de mesa en Grecia”. - Grasas y Aceites 20, pp. 12-24. 
Minguez, M., González, F., Pérez, C., Márquez, J., \& Fernández, M. (1970). Elaboración del pimiento para el relleno de aceitunas. Pelado químico y conservación en salmuera de baja graduación. II. Resultados de la campaña 1969-70. Grasas y Aceites 21, pp. 342-348.

González, F., Minguez, M., \& Fernández. M. (1972). La fermentación del pimiento empleado en el relleno de aceitunas verdes. Microbiol. Españ. 25, pp. 81-90.

Fleming, H. (1982). Fermented vegetables. Economic Microbiology. Fermented Foods, Vol. 7. pp 227-258. A.H. Rose (Ed), Academic Press, Inc. New York.

Rodrigo, M., Martínez, A., Alvarruiz, M. Lázaro, J., Fernández, M. y Navarro, A. (1984). Estado actual y avances en la conservación de pepinillos por fermentación"- Rev. Agroquim. Tecnol. Aliment. 24, pp. 453-466.

Santolaya, M. (2016). Análisis microbiológico de diferentes encurtidos. Universidad de Jaén-España.

Enríquez, M. A. (2018). Atmósfera modificada en la conservación de carne de trucha arcoíris (Oncorhynchus mykiss). NOVASINERGIA, ISSN 2631-2654, 1(1), 67-71.

https://doi.org/10.37135/unach.ns.001.01.08. 